\title{
THE TOXICITY OF RUBBERS AND PLASTICS USED IN TRANSFUSION-GIVING SETS
}

\author{
BY \\ C. N. D. CRUICKSHANK, CAROLINE HOOPER, H. B. M. LEWIS,* AND \\ J. D. B. MACDOUGALL \\ From the M.R.C. Unit for Research on the Experimental Pathology of the Skin, University of \\ Birmingham, the Regional Blood Transfusion Service, Birmingham, and the Department of Anatomy. \\ Queen's College, University of St. Andrews, Dundee
}

(RECEIVED FOR PUBLICATION JUNE 18, 1959)

The toxicity of different rubbers and plastics used in transfusion-giving sets has been investigated by examining their effects on $(a)$ cultures of chick embryo tissues, $(b)$ the oxygen uptake of guinea-pig skin tissue cultures, and (c) the growth of Str. pyogenes.

The results of the laboratory tests have been compared with the incidence of thrombophlebitis after prolonged transfusions through the various materials.

It was found that where the materials inhibited the growth of Str. pyogenes they were also toxic to tissue cultures, but that some materials which were toxic to tissue cultures did not inhibit bacterial growth.

The assessments of the relative toxicity of the materials tested by the two tissue culture methods were in agreement. The skin respiration studies, however, gave more information on the early effects of the toxic materials. The relative toxicity of the materials as revealed by these tests could be correlated with the differences in the incidence of thrombophlebitis following intravenous infusions administered through giving-sets assembled with the materials tested.

It is suggested therefore that the toxicity revealed by these tests is of clinical importance, and that tissue culture toxicity tests will prove to be of value in selecting rubbers and plastics for clinical purposes.

It has been shown that the incidence of thrombophlebitis following prolonged intravenous infusions varies with the material of which the transfusion-giving set is made (Handfield-Jones and Lewis, 1952; Medical Research Council, 1957). It is likely that this is due to differences in the liberation of toxic substances from the rubbers and plastics into the infusion fluid. It is therefore clearly desirable to devise a laboratory test by which the relative toxicity of these materials may be assessed. Such a test would have a wide application in medicine generally, as rubbers and plastics are frequently used in close contact with living tissues and for the storage of biological materials.

The suitability of plastics for use in surgery has been assessed by the implantation of samples in laboratory animals (Ingraham, Alexander, and Matson, 1947a, b). While this form of test is necessary to assess the long-term effects of the

*Present address: Blood Transfusion Centre, 62. East Terrace, Adelaide, S. Australia. materials, it has the disadvantage that the nonspecific reaction to the trauma of implantation tends to obscure any early toxic effects, so that, unless the toxic reaction is pronounced, the results tend to be equivocal (Barnes, 1953).

By investigation in the intact animal, polymethyl-methacrylate ("kallodent," " perspex") (Beck, Russell, Small, and Graham, 1945) and polyethylene ("polythene") (Ingraham et al., 1947b) have been found to be well tolerated by tissues. "Nylon," which has the advantage that it can be sterilized by autoclaving, has usually been found to be well tolerated as a suture material. These plastics can be obtained in a pure form. Certain other plastics, for instance polyvinyl chloride (P.V.C.), have to be compounded to produce materials with suitable physical properties. Materials of relatively low molecular weight are added as "plasticizers" and other substances as "stabilizers." These added substances may leach out in use, and many of them have been found to be irritating to tissues. 
Plasticized compounds are therefore usually suspect unless it can be demonstrated that they are not tissue irritants.

It has been known for some time that certain rubbers are toxic to living cells. Ranson (1937) reported that rubber was spermicidal, and that rubbers from different sources showed great differences in this respect. Gunz (1948) found rubber to be toxic to cultures of human leukaemic cells, and Lajtha (1952) to cultures of human bone marrow. During the development of a synthetic medium for animal cells in tissue culture, Parker, Morgan, and Morton (1951) observed that chance contact of the synthetic feeding mixtures with the rubber stoppers used to close the culture tubes often killed the cells within 48 hours. Exhaustive extraction with hot and cold solvents reduced the toxicity only slightly. They found that rubbers from different sources showed marked differences in their toxicity, but no sample was completely inert. However, MacDougall (1953) tested silicone rubbers and found them not to be toxic to chick embryo tissue cultures.

In this study the relative toxicity of a series of rubbers and plastics has been assessed by tissue culture methods. In one series of experiments the growth rate of chick embryo tissues in hangingdrop cultures was observed, and in a second series the oxygen uptake of guinea-pig ear skin slices in culture was measured over 24 hours. A similar test has been used for assessing the toxicity of antibiotics (Lawrence, 1959). The materials tested were certain rubbers and plastics on which data were available concerning the incidence of thrombophlebitis associated with their use. Some other materials were also tested for comparative purposes.

As a test for rubber transfusion equipment based on its effects upon the growth of Str. pyogenes has been prescribed by British Standard 2463 : 1954 , most of these materials were also tested for bacterial inhibitory substances.

\section{Materials}

The materials investigated were as follows:

Rubber 6107.*-A red natural rubber tubing, referred to as "tubing $A$ " by Handfield-Jones and Lewis (1952), which was manufactured for transfusion purposes from 1944 to 1951.

Rubber 6819.*-A red natural rubber tubing, based on the composition of the tubing referred to as "tubing D" by Handfield-Jones and Lewis (1952). It was manufactured for routine use from 1953 onwards, and inquiries revealed that this was the

\footnotetext{
* Manufactured by Messrs. William Warne and Co., Barking,
}

rubber used during 1956 to make up giving-sets at the North London, South London, Bristol, Birmingham, and Manchester blood transfusion centres. It was therefore the rubber with which the plastic was. compared at the centres in England which participated in the trial of plastic giving-sets (Medical Research Council, 1957). The Medical Research Council's Blood Transfusion Research Committee kindly supplied data for the centres using this rubber, not directly obtainable from the published report.

The plastic giving-set $\dagger$ tested was that used in the " thrombophlebitis trial" (Medical Research Council, 1957). A modified plastic giving-set based upon this design has recently been described by Jenkins, Stone, Knowles, Tovey, and Sharpe (1959).

The plastic giving-set provided materials of three: types:

Polyvinyl Chloride of Two Different Compositions. -(1) That used for the flexible tubing (referred to below as the P.V.C. tubing), and (2) that used for the stiffer drip tube, drip chamber, and casing of the filter chamber (referred to below as the P.V.C. casing).

Nylon.-The nylon tested was that used in the filter. When it was unexpectedly found to be toxic (see below) the composition of the nylon was. discussed with the manufacturer, who thought that there might be residual monomer in the material. The nylon was treated by the manufacturer to remove this substance; the treated material is referred to below as the monomer-free nylon.

Rubber.-The small piece of natural rubber tubing attached to the intravenous needle of the plastic giving-set (referred to below as rubber P.S.).

Tests were also made on silicone rubber D.S.R. 551, the silicone rubber referred to as "colour code yellow" by Wilkinson, Freeman, New, and Noad (1956), who used it for blood transfusions lasting two to four hours, other grades of silicone rubber, and a sample of polytetrafluoroethylene ("fluon "). \&

Before testing, the rubbers 6107 and 6819 and the silicone rubber were cleaned by the routine process for transfusion tubing (Handfield-Jones and Lewis, 1952); the plastics and rubber P.S. were taken directly from sterile giving-sets as supplied by the manufacturer.

\section{Methods}

Chick Embryo Cultures.-Primary outgrowths on coverslip preparations as described by Pomerat (1951) for testing drugs were used to assess the toxicity of the materials. The method was similar to that used by MacDougall (1953) for testing the toxicity of silicone rubber. The cells used were fibroblasts derived from the cardiac ventricles, nerve cells from the spinal cord, and epithelial cells from the intestines of 9-10-day chick embryos. In addition, the mixed

t Manufactured by Messrs. Capon Heaton and Co., Stirchley, Birmingham.

‡ Manufactured by the Dunlop Rubber Co., Cambridge Street, Manchester, 1.

\& Manufactured by Imperial Chemical Industries Ltd. 
population of cells obtained from 17-20-day chick embryo spleens was used. The tissues were divided into $1 \mathrm{c} . \mathrm{mm}$. fragments and explanted on standard $1 \frac{1}{4}$ in. square coverslips in a medium composed of equal parts of cockerel plasma and chick embryoric extract. The cockerel plasma was freshly prepared and contained no added heparin. The embryonic extract was also freshly prepared from 9-10-day chick embryos, minced by hand and diluted with an equal volume of Tyrode's solution. No antibiotics were used.

In the case of the experimental cultures, the material to be tested was brought close to the explanted tissue before clotting of the medium took place. Approximately $1 \mathrm{c} . \mathrm{mm}$. of material was used. The silicone rubber was sterilized by dry heat; the other materials were autoclaved.

Observations on the amount of growth, the contractility of muscular elements, and the cytological appearance of control and experimental cultures were made after incubation at $38^{\circ} \mathrm{C}$. for 18 hours, and thereafter twice daily until 72 hours. Some cultures were fixed in formol-Ringer or acetic alcohol and stained with Ehrlich's haematoxylin and eosin.

Skin Respiration.-Measurement of the respiration of skin slices was made by the technique described by Cruickshank (1954) using a sensitive microrespirometer, which gives accurate readings of the respiration of skin slices weighing approximately $10 \mathrm{mg}$. (wet weight). Skin slices were cut free-hand from the dorsum of the guinea-pig ear and suspended in a medium consisting of Krebs-Ringer phosphate (Field, 1948) $60 \%$, glucose, $0.2 \mathrm{M} 10 \%$, streptomycin, $500 \mu \mathrm{g} . / \mathrm{ml}$. $10 \%$, fresh guinea-pig serum $20 \%$. It will be noted that the amount of serum is less than that previously employed, as higher concentrations of serum have been found to mask minor toxic effects.

The materials were chopped into fine cubes of about 1 c.mm., sterilized by boiling, dried in hot air, and added to the medium, approximately $0.25 \mathrm{~g}$. being immersed in $0.5 \mathrm{ml}$. of medium in both culture and control cups. In the case of the fine nylon filter which was examined, only about $0.05 \mathrm{~g}$. could be immersed in $0.5 \mathrm{ml}$. of medium because of its greater bulk. In each experiment the respiration of three control amounts of skin was compared with the respiration of corresponding portions from the same animal in the presence of the test material.

At the end of the experiment the skin slices were fixed in $10 \%$ buffered formalin, sections prepared, and these stained with haematoxylin and eosin.

Bacterial Inhibition.-The test described in British Standard 2463:1954, Appendix B, was used, and, at the suggestion of Dr. K. B. Rogers, tests were also made by the following pour-plate technique. A strain of Str. pyogenes was grown for 18 hours in $1 \%$ glucose-broth and then diluted $1 / 100$ in warm "tryptone" water. Then $0.2 \mathrm{ml}$. of the diluted culture was added, together with $1.0 \mathrm{ml}$. of horse blood, to $18.8 \mathrm{ml}$. of molten heart-infusion agar. The test materials were placed on a layer of heart-infusion agar in a Petri dish. The "seeded" blood agar was then found to give a sandwich plate with the test materials imbedded in the upper layer. The plates were incubated at $37^{\circ} \mathrm{C}$. for 18 hours and were photographed within a few hours of their removal from the incubator.

\section{Results}

Clinical Findings.-The incidence of thrombophlebitis following intravenous infusions administered through National Blood Transfusion Service giving-sets assembled with rubbers 6107 and 6819 and the Medical Research Council plastic giving-set is shown in Table I. The data

TABLE I

INCIDENCE OF THROMBOPHLEBITIS AFTER INTRAVENOUS INFUSIONS LASTING FROM 13 TO 47/48 HOURS ADMINISTERED THROUGH RUBBER AND PLASTIC GIVING-SETS

\begin{tabular}{|c|c|c|c|}
\hline \multirow{2}{*}{$\begin{array}{l}\text { Type of } \\
\text { Giving-set } \\
\text { and Tubing }\end{array}$} & \multirow{2}{*}{$\begin{array}{c}\text { Total } \\
\text { Infusions }\end{array}$} & \multicolumn{2}{|c|}{ Thrombophlebitis } \\
\hline & & No. of Cases & $\%$ of Total \\
\hline $\begin{array}{l}\text { *N.B.T.S., rubber } 6107 \\
+ \text { N.B.T.S., , } 6819 \\
\text {; M.R.C., plastic } \quad \text {.. }\end{array}$ & $\begin{array}{r}64 \\
101 \\
130\end{array}$ & $\begin{array}{l}42 \\
46 \\
33\end{array}$ & $\begin{array}{l}66 \\
46 \\
25\end{array}$ \\
\hline
\end{tabular}

$\chi^{2}$ calculated with Yates's correction gives the following values for 1 degree of freedom: Rubber 6107 with $6819=5.6, P<0.02$
, 6819 , plastic $=9.4, P<0.01$

* Data from Handfield Jones and Lewis (1952), tubing A, added to previously unpublished observations (1953), viz.:

\begin{tabular}{|c|c|c|c|}
\hline & & $\begin{array}{c}\text { Total } \\
\text { Infusions }\end{array}$ & $\begin{array}{c}\text { No. of } \\
\text { Cases }\end{array}$ \\
\hline \multirow{2}{*}{\multicolumn{2}{|c|}{$\begin{array}{l}\text { Tubing A }\left\{\begin{array}{l}\text { Preliminary survey } \\
\text { Control series }\end{array}\right. \\
\text { Additional observations } \ldots\end{array}$}} & $\begin{array}{l}25 \\
19 \\
20\end{array}$ & $\begin{array}{l}18 \\
11 \\
13\end{array}$ \\
\hline & & 64 & 42 \\
\hline
\end{tabular}

† Data from Medical Research Council thrombophlebitis trial (see text).

‡ Data from Medical Research Council (1957).

concerning the giving-sets assembled with rubber 6107 represent the addition of three consecutive series of observations. These are the "preliminary survey" and "control series" of observations on the incidence of thrombophlebitis associated with "tubing A" made by Handfield-Jones and Lewis (1952) together with a previously unpublished series made by the same authors in 1952-53. The frequency of thrombophlebitis associated with this tubing remained constant $(0.70>\mathrm{P}>0.50)$, and so it appears reasonable to compare these data with the observations made in the M.R.C. trial in 1956. The infusion period of 13 to 48 hours was chosen for this comparison, as there were insufficient data to make a fair comparison over longer or shorter periods. It will be seen that, in infusions lasting 13-48 hours, rubber 6107 was associated with an 
TABLE II

CULTURES OF CHICK EMBRYO TISSUES IN CONTACT WITH VARIOUS MATERIALS

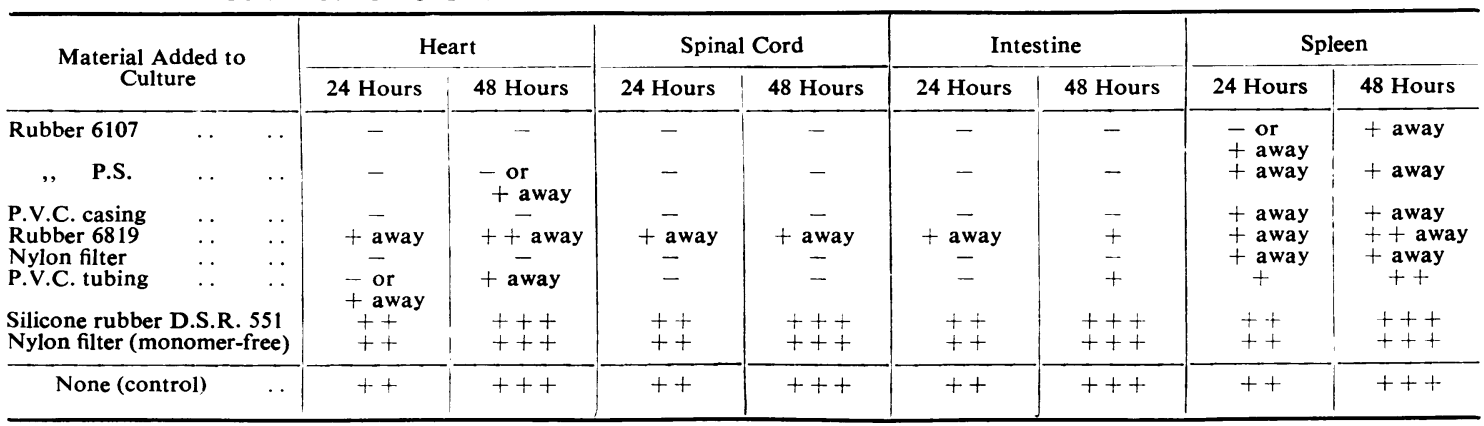

$-=$ No growth. $\quad+=$ Slight growth (less than the amount seen in control cultures at 24 hours). $\quad+\quad=$ An amount of growth similar to that seen in control cultures at 24 hours. $\quad+++=$ An amount of growth similar to that seen in control cultures at 48 hours. $\quad+$ Away or ++ away signifies that the growth indicated by the + or ++ sign took place only on the side of the explant remote from the added material.

incidence of thrombophlebitis of $66 \%$, rubber 6819 with $46 \%$, and the M.R.C. plastic set with only $25 \%$.

Chick Embryo Cultures.-The results of 430 cultures are summarized in Table II. Examples of normal growth in a control and an experimental culture are shown in Figs. 1 and 3. Total inhibition of a culture is shown in Fig. 2. Fig. 4 illustrates a somewhat different effect: growth has taken place only at the side of the explant furthest from the test material. This is recorded in Table II as " + away." In assessing intermediate degrees of inhibition the amount of growth in the test cultures was compared with that of the corresponding controls and recorded in a plus notation. This was considered preferable to the recording of growth rates in quarter diameters of the microscopic field as described by Pomerat (1951), as several tissues with varying growth rates were used.

It is obvious from the results shown in Table II that rubber 6107 , the P.V.C. casing, the nylon filter, and rubber P.S. were extremely toxic to these cultures and were indistinguishable in this test. Rubber 6819 caused less inhibition of growth, although most of this was away from the rubber. The P.V.C. tubing was less toxic to cultures of spleen than rubber 6819 , but on the other tissues which grew more slowly its effect was either the same or slightly more toxic than rubber 6819. The silicone rubber and the monomer-free nylon filter caused no inhibition.

Physiological functions were of little value as an indication of toxicity, e.g., the heart might continue to pulsate for 24 hours although outgrowth had been completely inhibited. The examination of both living and stained cultures, however, showed that, where growth was less than in the corresponding control cultures, various cytological abnormalities such as poor staining reactions, diminished or absent mitoses, and varying numbers of cells with pyknotic nuclei were also present.

By other experiments, not included in Table II, it was shown that tissue from younger embryos was more sensitive to toxic influences than the corresponding tissue from older embryos. Attempts to increase the sensitivity of the tests by reducing the proportion of plasma in the medium were not successful, as sufficient reduction could not be made while maintaining the minimum amount of firmness necessary in the clot.

Repeated autoclaving appeared to reduce the toxicity of rubber 6819 , although cells grown in immediate contact were still necrotic and those further away were excessively fatty and far from normal. The toxicity of rubber 6107 remained unchanged after many hours of autoclaving.

The other grades of silicone rubber and the "fluon" which were tested but not shown in Table II were not found to be toxic.

Skin Respiration.-The effects of the various materials on the respiration of guinea-pig ear skin are shown in Table III. Fig. 5 illustrates the relative depression of respiration in relation to time caused by the four principal types of tubing tested. This figure emphasizes the rapid action of the more toxic materials.

As in the chick embryo tissue cultures, rubber 6107 proved extremely toxic, its effect being manifest within two hours. Rubber 6819, the P.V.C. casing, and rubber P.S. did not significantly depress the skin respiration until the second two hours of observation. The nylon filter had no effect in four hours although causing total inhibition of respiration in 24 hours. The P.V.C. 


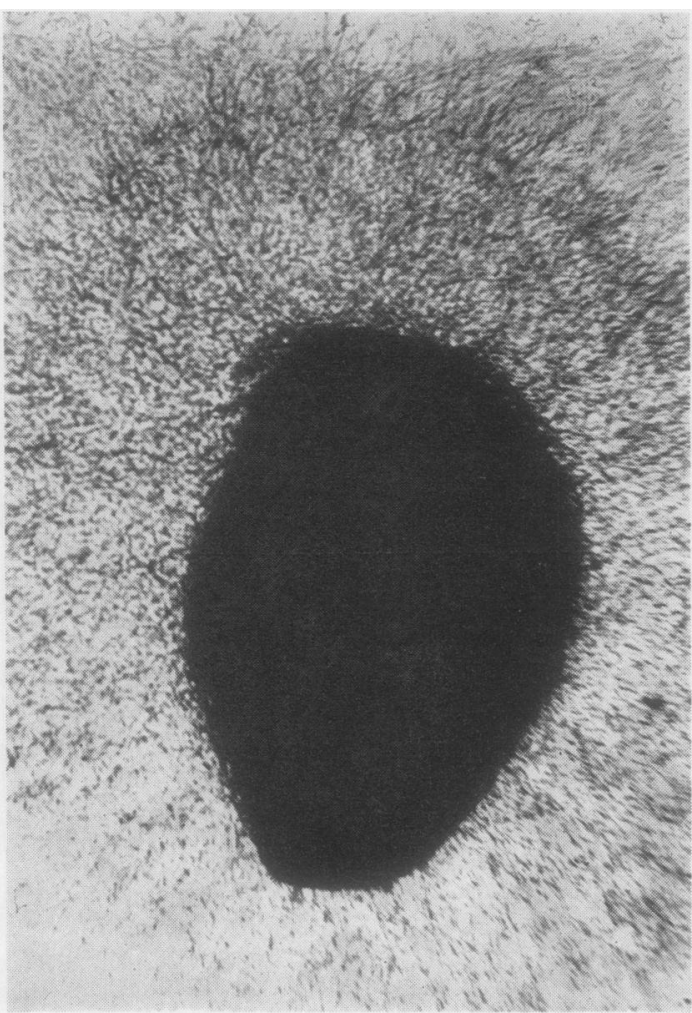

FIG. 1.-Control culture of 10-day chick embryo heart.

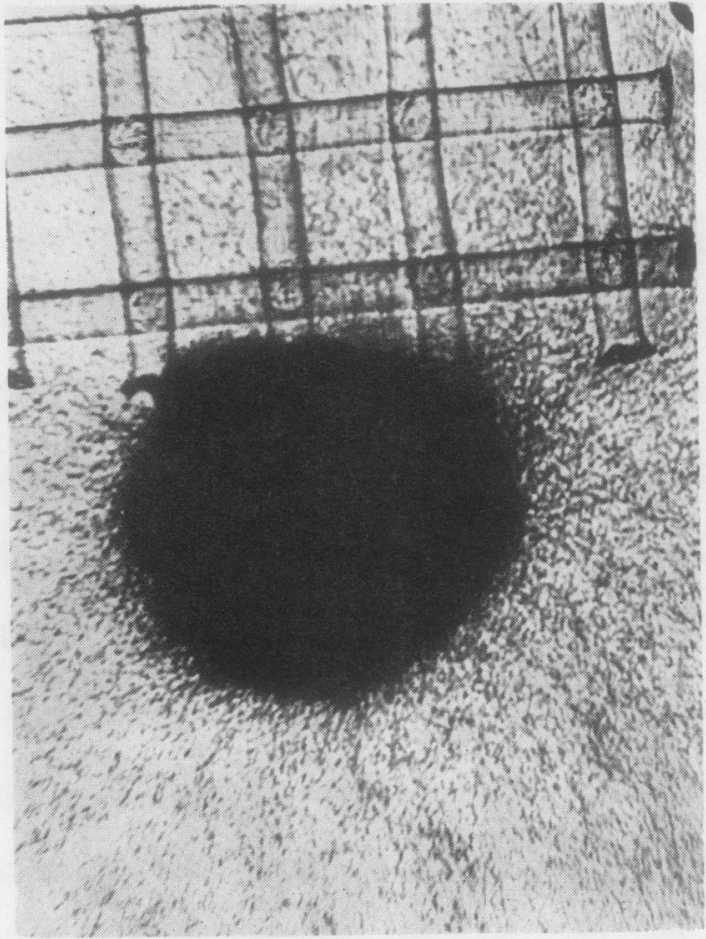

FIG. 3.-Culture of 10-day chick embryo heart in contact with a fragment of the monomer-free nylon filter. Growth is similar in extent to that of the control culture.

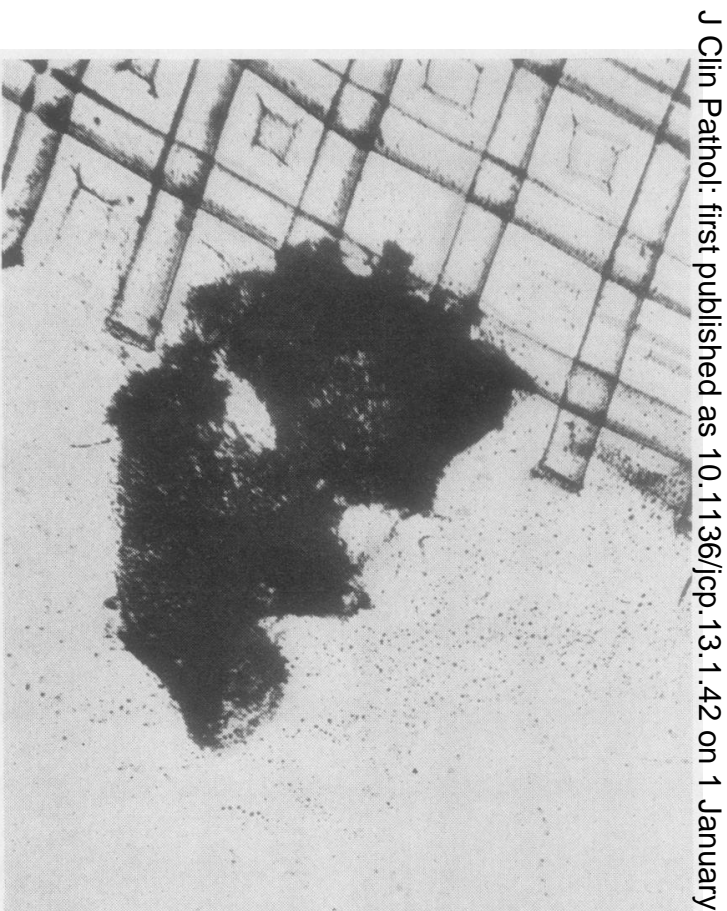

Fig. 2-Culture of 10-day chick embryo heart in contact with a $\vec{\varphi}$ fragment of the original nylon filter. Note complete inhibition of growth.

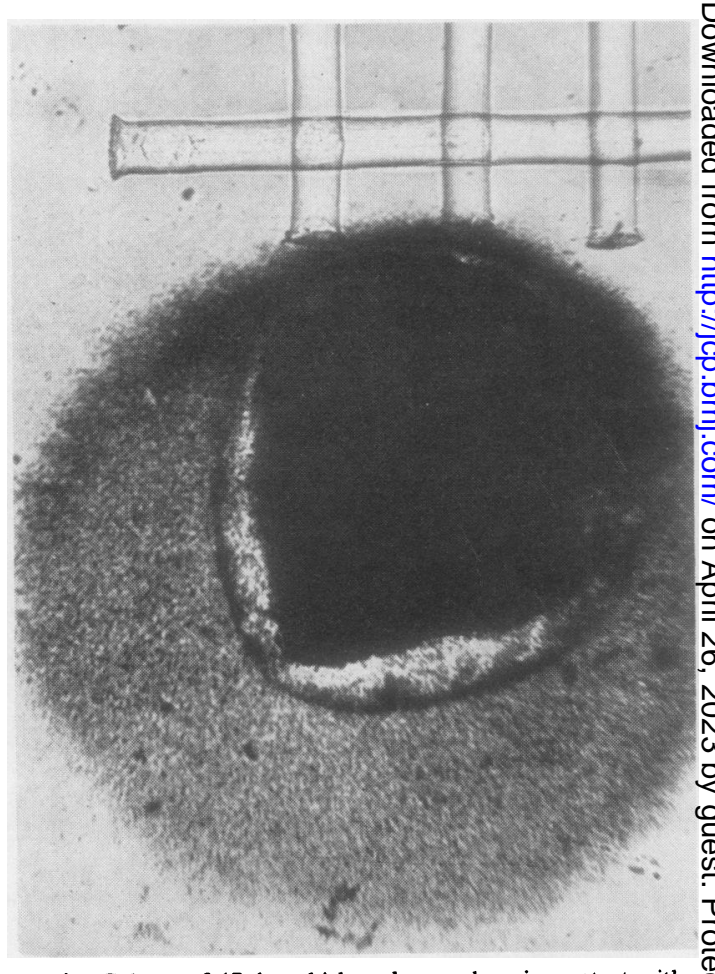

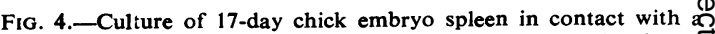
fragment of the original nylon filter. Growth is restricted, and has taken place only in the direction away from the nylon filter?

FIGS. 1-4-Chick embryo tissues in hanging drop preparations of equal parts of cockerel plasma and chick embryonic extract. Appearancers. after thrce days' incubation at $38^{\circ}$ C. Stained with Ehrlich's haematoxylin and eosin. $\times 30$. 
TABLE III

THE EFFECTS OF RUBBERS AND PLASTICS ON THE RESPIRATION OF SKIN IN VITRO

\begin{tabular}{|c|c|c|c|c|c|}
\hline \multirow{2}{*}{ Material } & \multirow{2}{*}{$\mid \begin{array}{c}\text { Time } \\
(\text { Hours })\end{array}$} & \multicolumn{2}{|c|}{$\begin{array}{c}\text { Oxygen Uptake } \\
(\mu 1 . / \mathbf{m g} . / \mathrm{hr} .)\end{array}$} & \multirow{2}{*}{$\begin{array}{l}\text { Difference } \\
\text { Test-Control } \\
\text { 土S.E. }\end{array}$} & \multirow[t]{2}{*}{$\begin{array}{c}\% \\
\text { Inhib } \\
\text { ition }\end{array}$} \\
\hline & & Test & Control & & \\
\hline & $\begin{array}{c}0-2 \\
2-4 \\
22-24\end{array}$ & & & $\begin{array}{l}-0.20 \pm 0.05^{*} \\
-0.74 \pm 0.05^{*} \\
-0.85 \pm 0.07^{*}\end{array}$ & $\begin{array}{l}18 \\
61 \\
96\end{array}$ \\
\hline & $\begin{array}{c}0-2 \\
2-4 \\
22-24\end{array}$ & & & $\begin{array}{l}-0.20 \pm 0.11 \\
-0.47 \pm 0.09 * \\
-0.76 \pm 0.06 *\end{array}$ & $\begin{array}{l}17 \\
41 \\
95\end{array}$ \\
\hline & $\begin{array}{c}0-2 \\
2-4 \\
22-24\end{array}$ & & & $\begin{array}{l}-0.10 \pm 0.06 \\
-0.26 \pm 0.05^{*} \\
-0.88 \pm 0.04^{*}\end{array}$ & $\begin{array}{l}10 \\
21 \\
94\end{array}$ \\
\hline & $\begin{array}{c}0-2 \\
2-4 \\
22-24\end{array}$ & $\begin{array}{l}0.79 \pm 0.03 \\
0.71 \pm 0.04 \\
0.14 \pm 0.02\end{array}$ & & $\begin{array}{l}-0.07 \pm 0.04 \\
-0.21 \pm 0.04 * \\
-0.71 \pm 0.03 *\end{array}$ & $\begin{array}{r}8 \\
23 \\
84\end{array}$ \\
\hline & $\begin{array}{c}0-2 \\
2-4 \\
22-24\end{array}$ & $\begin{array}{l}1.08 \pm 0.04 \\
1.08 \pm 0.03 \\
0.03 \pm 0.01\end{array}$ & & $\begin{array}{l}+0.13 \pm 0.05 \\
+0.09 \pm 0.04 \\
-0.75 \pm 0.01 *\end{array}$ & $\begin{array}{r}0 \\
0 \\
96\end{array}$ \\
\hline & $\begin{array}{c}0-2 \\
2-4 \\
22-24\end{array}$ & $\begin{array}{l}1.06 \pm 0.04 \\
1.02 \pm 0.03 \\
0.56 \pm 0.01\end{array}$ & $\begin{array}{l}1 \cdot 18 \pm 0 \\
1 \cdot 17 \pm \\
0 \cdot 93 \pm 0\end{array}$ & $\begin{array}{l}-0.12 \pm 0.06 \\
-0.15 \pm 0.05 * \\
-0.37 \pm 0.01^{*}\end{array}$ & $\begin{array}{l}10 \\
13 \\
40\end{array}$ \\
\hline $\begin{array}{l}\text { Silicone } \\
\text { rubber } \\
\text { (D.S.R. } \\
\text { 551) }\end{array}$ & $\begin{array}{c}0-2 \\
2-4 \\
22-24\end{array}$ & $\begin{array}{l}1 \cdot 10 \pm 0.03 \\
1 \cdot 14 \pm 0.04 \\
0.93 \pm 0.03\end{array}$ & $\begin{array}{l}1 \cdot 15 \pm 0.06 \\
1 \cdot 17 \pm 0.07 \\
0.96 \pm 0.07\end{array}$ & $\begin{array}{l}-0.05 \pm 0.0 \\
-0.03 \pm 0.0 \\
-0.03 \pm 0.0\end{array}$ & $\begin{array}{l}4 \\
3 \\
3\end{array}$ \\
\hline $\begin{array}{l}\text { Nylon } \\
\text { filter } \\
\text { (mono- } \\
\text { mer-free) }\end{array}$ & $\begin{array}{c}0-2 \\
2-4 \\
22-24\end{array}$ & $\begin{array}{l}0.97 \pm 0.02 \\
1.04 \pm 0.03 \\
0.93 \pm 0.03\end{array}$ & $\begin{array}{l}1 \cdot 16 \pm 0.08 \\
1 \cdot 19 \pm 0.07 \\
1.05 \pm 0.05\end{array}$ & $\begin{array}{l}-0.19 \pm 0.08 \\
-0.15 \pm 0.08 \\
-0.12 \pm 0.06\end{array}$ & $\begin{array}{l}16 \\
13 \\
11\end{array}$ \\
\hline
\end{tabular}

* The difference between the test mean and the control mean is significant by Student's $t$ test $(P<0.05)$.

$\dagger$ Mean of three experiments \pm S.E. mean.

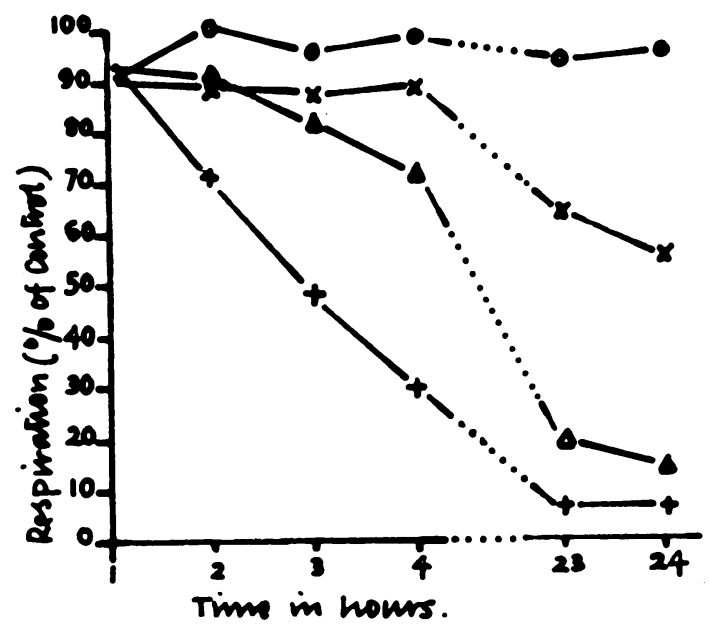

FIG. 5.-The mean respiratory rate at hourly intervals of portions of skin in three respirometers is expressed as a percentage of three control portions. $O=$ Silicone rubber (D.S.R. 551); $X=$ P.V.C. tubing; $\Delta=$ rubber $6819 ;+=$ rubber 6107 .

tubing significantly decreased respiration in four hours, but at 24 hours it had less effect than any of the other materials exhibiting toxicity. The silicone rubber and monomer-free nylon were without effect. The rapid effect of rubber 6107 suggested that the toxic substance might be freely diffusible, and so a further experiment was made to see if it could be removed. The chopped rubber was boiled in repeated changes of distilled water for eight hours: this treatment removed the toxicity. However, similar treatment of rubber 6819 only slightly reduced its toxicity.

Sections prepared after 24 hours' culture showed that the skin remained normal only in the presence of the silicone rubber D.S.R. 551 and the monomer-free nylon filter. The P.V.C. tubing caused minor abnormalities such as occasional patches of necrosis, while the other materials caused severe histological damage.

Bacterial Inhibition.-The results of the tests by the method described in the British Standard $2463: 1954$ and by the pour-plate technique were in agreement. The pour-plate technique was, however, found to be more sensitive, and the results were more easily photographed.

The effects of the rubbers in a pour-plate are shown in Fig. 6. From rubber 6107 a substance inhibitory to the growth of bacteria has diffused outwards. Beyond the zone of unaltered blood agar the haemolysis is caused by the growth of Str. pyogenes; next to the rubber a translucent ring is produced by a haemolytic agent diffusing from the rubber; rubber P.S. is also inhibitory. Rubber 6819 and the silicone rubber are not inhibitory. In Fig. 7 the different effects of the P.V.C.s can be seen; the P.V.C. casing is inhibitory, the P.V.C. tubing is not inhibitory. The original nylon filter was found to be inhibitory, but the monomer-free nylon was not inhibitory.

As it had been found possible to remove the substances toxic to guinea-pig skin from rubber 6107, a further experiment was made to see if the bacterial inhibitory substance could also be removed. Transverse sections of tubing, $2 \mathrm{~mm}$. thick, were boiled in half-hourly changes of distilled water for eight hours. The rings of rubber were removed after one, two, four, and eight hours' treatment. Their effect on bacterial growth can be seen in Fig. 8 . The inhibitory substance was gradually removed, but a trace was still present after four hours' boiling in eight changes of water. After eight hours' treatment the rubber was not inhibitory.

\section{Discussion}

As information is available concerning the incidence of thrombophlebitis following intravenous infusions given through the rubbers and 


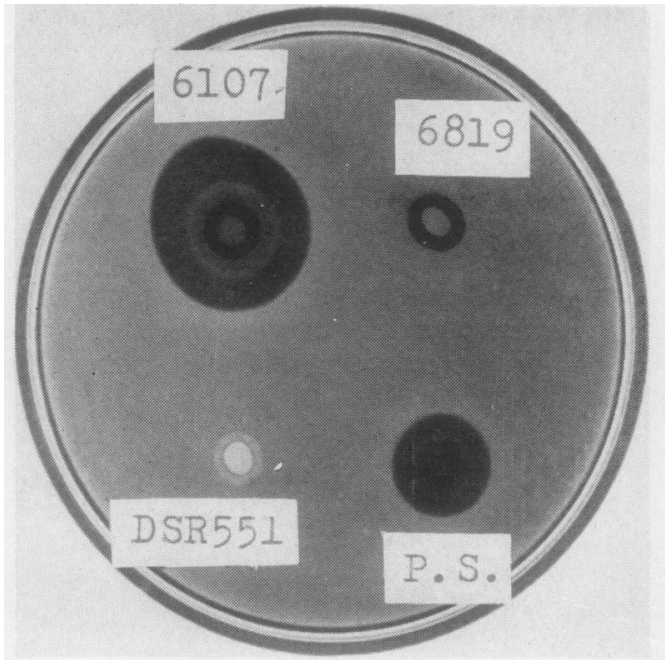

FIG. 6

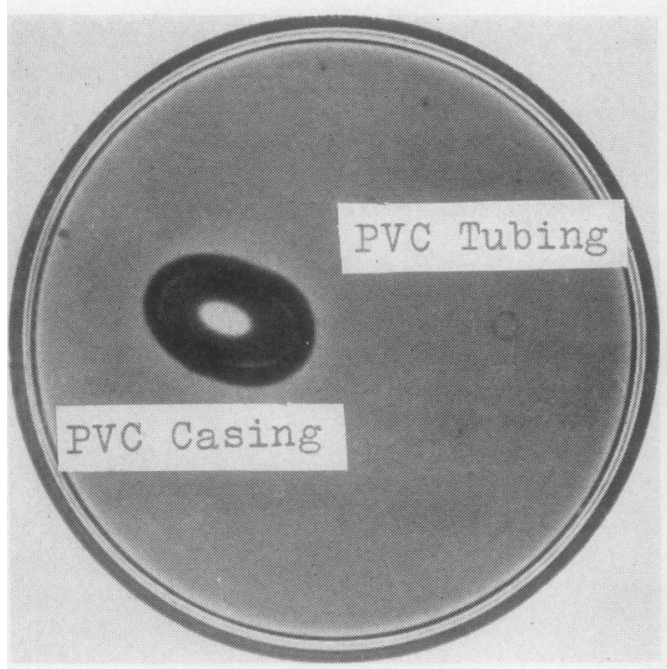

FIG. 7

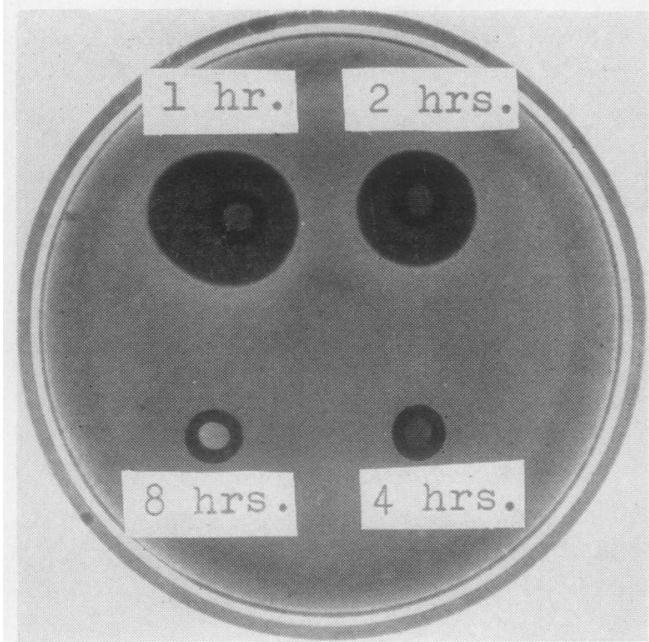

FIG. 8

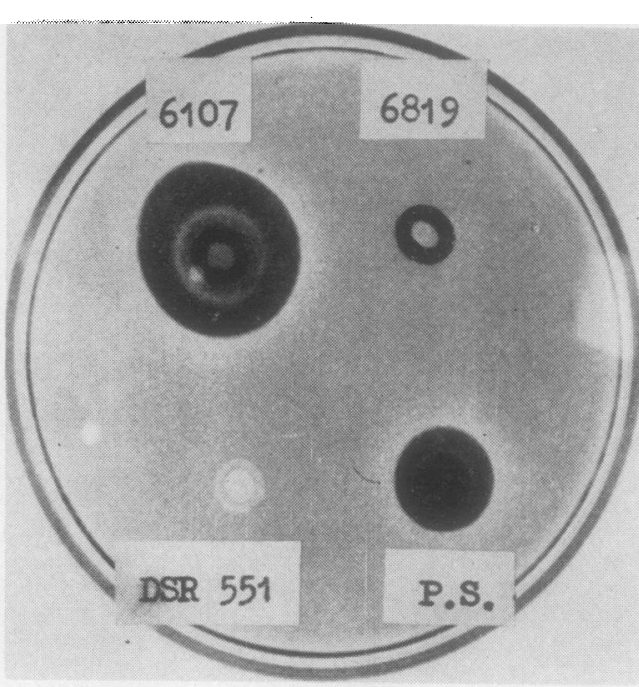

FIG. $6 a$

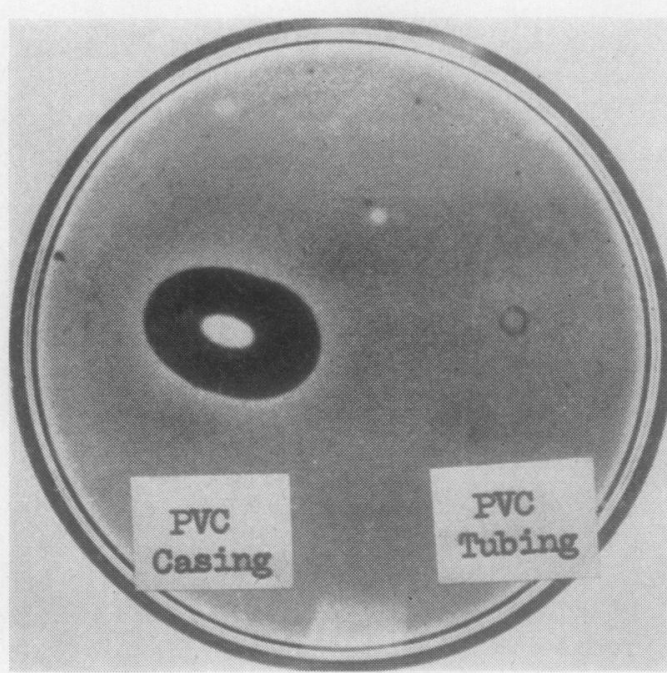

FIG. $7 a$

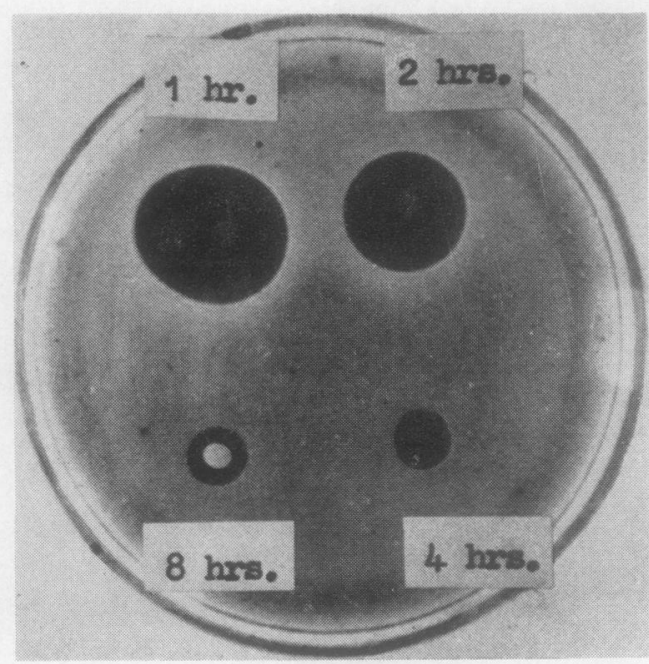

FIg. $8 a$ 
plastics tested, it is possible to correlate clinical findings with laboratory tests. At the same time a comparison can be made of the effects of these materials on the growth of chick embryo explants, the respiration of guinea-pig skin, and the growth of Str. pyogenes.

The two tissue culture tests were in agreement concerning the relative toxicity of rubbers 6107 - and 6819. Rubber 6107 was found to be extremely toxic and rubber 6819 less toxic to all the chick embryo tissues and to guinea-pig skin, although, besides differences in the tissues, there were also differences in the culture media and the methods of observation. This assessment, therefore, agrees with the clinical findings, the respective incidence of thrombophlebitis when these rubbers were used being $66 \%$ and $46 \%$ for infusions lasting 13-48 hours.

Both methods of testing also showed that the silicone rubber and the "monomer-free" nylon were not toxic, and that the small piece of rubber from the plastic set (rubber P.S.) was highly toxic.

The toxicity of the P.V.C. casing and the original nylon filter as assessed by their effects on the respiration of skin at 24 hours agreed with the results of chick embryo tests, and both in this assessment were as toxic as rubber 6107 . However, the skin respiration tests gave additional information, as early effects could be observed which enabled distinctions to be made between the materials. The nylon filter had no effect in the first four hours, and the P.V.C. casing, though causing some depression of respiration, had much less effect than rubber 6107 . On this basis they are both less toxic than rubber 6107. In comparison with rubber 6819 , the P.V.C. casing is of the same order of toxicity, and the nylon filter is less toxic.

As tested on chick embryo cultures and on skin respiration the P.V.C. tubing was less toxic than any of the other materials used in the givingsets. Its advantage in this respect was most clearly demonstrated by the respiration tests, which showed it to be inferior only to the silicone rubber and monomer-free nylon filter.

It is impossible to be sure what contribution each component of the plastic giving-set makes to its potential total toxic effect in clinical use. It is likely that the relative surface areas exposed to the infusion fluid are of importance. It has been calculated that, of the total surface area in contact with the infusion fluid, the proportionate surface areas exposed are P.V.C. tubing $54 \%$, P.V.C. casing $21 \%$, nylon filter $22 \%$, rubber P.S. $1 \%$, and other parts (coupling needle and Luer adaptor) $3 \%$. It is likely, therefore, that the results in vitro are consistent with the reduced incidence of thrombophlebitis when the set is used. It would be of interest to know if the use of a set completely free from toxic effects in vitro could achieve a further reduction in the incidence of thrombophlebitis. Other factors, for instance, the $p \mathrm{H}$ of the infusion fluids, have been postulated as causes of this complication. It is well known that autoclaved dextrose solutions have a $p H$ of about 4 (Todd, 1951) and it has been shown by Horvitz, Sachar, and Elman (1943) that the intravenous infusion of amino-acid solutions of $p H$ 4.6 into dogs causes more venous damage than the same solutions neutralized to $p H$ 7.3. It is, however, uncertain whether acid isotonic dextrose solutions cause venous damage in man (Bolton Carter, Milne, and Whittet, 1952 ; Page, Raine, and Jones, 1952). As suggested by Page et al., any beneficial effect which occurred in these investigations from adjusting the $p \mathrm{H}$ of the dextrose solutions was probably obscured by toxic substances liberated from the tubing of the giving-sets used. In any further clinical investigations of this subject it would seem desirable to use giving-sets composed of materials which have been demonstrated to be free of toxic effects in vitro.

The bacterial inhibition test appears to be of limited value. All the materials which inhibited the growth of Str. pyogenes were found to be toxic. However, rubber 6819 and the P.V.C. tubing which did not inhibit bacterial growth were nevertheless toxic in both tissue culture tests. It is clear, therefore, that this test, though of some value, is an unreliable guide to the selection of suitable rubbers and plastics, and its use will exclude only a proportion of potentially harmful materials.

Prolonged extraction in repeated changes of water removed the toxicity (and also the bacterial inhibitory substance) from rubber 6107, while repeated autoclaving had no effect on its toxicity. In contrast, the toxicity of rubber 6819 was only slightly reduced both by prolonged boiling and by autoclaving. It is doubtful whether this has any practical application for clinical purposes, but the effects of these treatments on the toxicity of tubing must obviously be taken into account in any comparative tests.

The effect of rubber 6107 on skin respiration suggested that the toxic substance was freely diffusible, and it is interesting to note that Barnes (1953) came to the same conclusion from observing its effects after subcutaneous implantation in the rat. $\mathrm{He}$ found that it invariably 
produced an acute inflammatory reaction with oedema and round cell infiltration, which subsided after 14 days. Samples left in place for three months excited no reaction and were surrounded by a minimum of fibrous tissue. Nevertheless, isotonic saline solutions left in contact with this rubber at room temperature for 72 hours, or autoclaved at $121^{\circ} \mathrm{C}$. in contact with it for 30 minutes (ratio of saline to rubber surface, $1 \mathrm{ml}$.: 8.4 sq. $\mathrm{cm}$.), were without effect when $0.25 \mathrm{ml}$. was injected intravenously into mice, or when $1.0 \mathrm{ml}$. was injected intraperitoneally on three successive days. The same solutions when injected intradermally into a rabbit which had been given pontamine blue intravenously to test for increased capillary permeability also had no effect. Rubber 6819 was negative in all these tests.

It was surprising to find that the original nylon filter was toxic. Surgical sutures are not regarded as toxic and this fact was confirmed by subsequent tissue culture tests on a sample. It was suggested by the manufacturer that the presence of free monomer might be the cause of the toxicity, as the nylon monomer contains highly reactive end-amino groups. The non-toxicity of the monomer-free filters subsequently supplied provides confirmation.

The potential toxicity of some rubbers is now fairly widely recognized, but the potential toxicity of the plastics which are tending to replace rubber for many purposes is not always appreciated. Tissue culture tests can give valuable help in the selection of suitable materials for clinical trials. Those which are toxic to tissue cultures would appear to be better avoided. But a negative result in a tissue culture test will not, of course, indicate that the material will be non-reactive when implanted in tissue. Tubes of silicone rubber, for instance, have been found to be not well tolerated in the brain (Dimant, 1955). Several plastics have been found to be carcinogenic in rodents after one to two years' subcutaneous implantation (Oppenheimer, Oppenheimer, Danishefsky, Stout, and Eirich, 1955).

It is probable that tissue culture tests will be chiefly of value in assessing the suitability of rubbers and plastics for use as catheters, endotracheal tubes, etc., and for apparatus used in contact with fluids which are infused, as in blood transfusion giving-sets, heart-lung machines, etc.
It is possible that tissue culture tests might show variation in the toxicity of the plastic containers used for storing blood. Some of these have had deleterious effects on the red cells stored in them (Wall, Buckley, and Doan, 1953 ; Strumia, Colwell, and Ellenberger, 1955). These tests will probably also be found to be of value in testing batches of the selected variety of plastic (or rubber) before it is used. This would be of particular importance when the exact composition of the material is unknown and possibly subject to variation. Detailed information on the composition of rubbers and plastics is unfortunately not often available for publication, and, in some instances, the manufacturers of an article may themselves not know the exact composition of the compounds supplied to them by the manufacturers of the basic material.

We should like to thank Dr. R. P. C. HandfieldJones for permission to quote unpublished observations made jointly with one of us (H. B. M. L.) ; Mr. J. E. Dowse, A.I.M.L.T., for assistance with the bacterial inhibition tests ; and Mr. A. Boot, of Messrs. Capon Heaton \& Co., for his co-operation. We are also indebted to Miss A. H. Ogilvie and Mr. A. S. Pyper for technical assistance.

\section{REFERENCES}

Barnes, J. M. (1953). Personal communication. Beck, D. J. K., Russell, D. S., Small, J. M., and Graham, M. P.

Carter, J. F. Bolton, Milne, E. H., and Whittet, T. D. (1952). Lancet, 2,660 .

Cruickshank, C. N. D. (1954). Exp. Cell Res., 7, 374.

Dimant, S. (1955). Lancet, $2,727$.

Field, J. (1948). Meth. med. Res., 1, 299.

Gunz, F. W. (1948). Brit. J. Cancer, $2,29$.

Handfield-Jones, R. P. C., and Lewis, H. B. M. (1952). Lancet, 1, 585 .

Horvitz, A., Sachar, L. A., and Elman, R. (1943). J. Lab. clin. Med., 28,842 .

Ingraham, F. D., Alexander, E., and Matson, D. D. (1947a). New Engl. J. Med., 236, 362 and 402.

(1947b). J. Amer. med. Ass., 135, 82.

Jenkins, W. J., Stone, B., Knowles, G. S. A., Tovey, G. H., and Sharpe, R. A. (1959). Lancet, 1, 139.

Lajtha, L. G. (1952). J. clin. Path., 5, 67.

Lawrence, J. C. (1959). Brit. J. Pharmacol., 14, 168.

MacDougali, J. D. B. (1953). Nature (Lond.), 172, 124

Medical Research Council (1957). Report of sub-committee, Lancet, 1, 595 .

Oppenheimer, B.S., Oppenheimer, E. T., Danishefsky, I., Stout, A. P., and Eirich, F. R. (1955). Cancer Res. 15, 333.

Page, B. H., Raine, G., and Jones, P. F. (1952). Lancet, 2, 778.

Parker, R. C., Morgan, J. F., and Morton, H. J. (1951). Proc. Soc. exp. Biol. (N.Y.), 76, 444.

Pomerat, C. M. (1951). Meth. med. Res., 4, 266.

Pomerat, C. M. (1937). Mancet, 1, 1400.

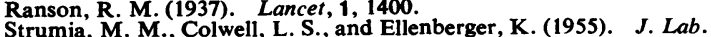
clin. Med., 46, 225.
ctrumia, M. M. Colwell,

Todd, R. M. (1951). Lancet, 1, 982.

Wall, R. L. Buckley, N. M., and Doan, C. A. (1953). J. Lab. clin. Med., 42, 674 .

Wilkinson, J. F., Freeman, G. G., New, N., and Noad, R. B. (1956) Lancet, 2, 621 . 